Ökkeş Hakan Miniksar ๑

Aytaç Yücel ๑

Mustafa Said Aydoğan $\odot$

Füsun Kaya ๑

Türkan Togal ๑

\title{
Green Discoloration of Urine After Propofol Infusion: A Case Report
}

Çıkar Çatışması: Çıkar çatışması yoktur.

Finansal Destek: Bu çalışma, herhangi bir fon tarafından desteklenmemiştir. Hasta Onamı: Hastalardan aydınlatılmış onam alınmıştır.
Conflict of Interest: There is no conflict of interest.

Funding: The authors declared that this study has received no financial support. Informed Consent: Informed consent was obtained from the patients.

Cite as: Miniksar ÖH, Yücel A, Aydoğan MS, Kaya F, Togal T. Propofol infüzyonu sonrası idrarın yeşil renk değişikliği: Bir olgu sunumu. GKDA Derg. 2020;26(4):267-71.

öz

Propofol infüzyonu sonrası idrarda yeşil renk değişikliği geri dönüşümlü ve nadir karşılaşılan bir klinik durumdur. Yoğun bakım hastasında idrarda yeșil renk değișikliği ile karșılaşan klinisyen en başta endişe duymaktadır. Birçok klinisyen bu ender duruma yabancıdır. Burada, HELLP Sendromu ile takip edilen, postoperatif yoğun bakımda devamlı propofol infüzyonu uygulaması başladıktan 40 saat sonra idrarda yeşil renk değiş̧ikliği olan ve propofol kesildikten 6 saat sonra kendiliğinden normale dönen olgu sunulmuştur. Yaygın kullanılan propofole bağlı böyle bir geri dönüşümlü ve ender görülen klinik durumu bilmek gereksiz endişeyi azaltacak, gereksiz antibiyotik kullanımını ve laboratuvar testlerini önleyecektir.

Anahtar kelimeler: anestezi, propofol, yeşil idrar

\section{ABSTRACT}

Green discoloration of urine after propofol infusion is a reversible and rarely encountered clinical condition. In the intensive care patient, the clinician who is faced with a green color change in the urine is anxious primarily. Many clinicians are unfamiliar with this rare situation. Here, a patient who was followed up with HELLP Syndrome, had green color change in urine 40 hours after application of continuous propofol infusion in postoperative intensive care unit and returned to normal 6 hours after propofol discontinuation. Knowing such a reversible and rare clinical condition due to the commonly used propofol will reduce unnecessary anxiety and prevent unnecessary antibiotic use and laboratory tests.

Keywords: anesthesia, propofol, green urine
Received/Geliş: 13.06 .2020

Accepted/Kabul: 01.07.2020 Published Online/Online yayın: 31.12 .2020

Ökkeş Hakan Miniksar Yozgat Bozok Üniversitesi Tıp Fakültesi Anesteziyoloji ve Reanimasyon Anabilim Dalı Yozgat, Türkiye hminiksar@yahoo.com ORCID: 0000-0001-5645-7729

A. Yücel 0000-0003-0270-8339 M. S. Aydoğan 0000-0002-7106-1156

T. Togal 0000-0003-1345-5226

Inönü Üniversitesi Tıp Fakültesi Anesteziyoloji ve Reanimasyon Anabilim Dalı Malatya, Türkiye

F. Kaya 0000-0001-9818-014X Kahramankazan Hamdi Eriş Devlet Hastanesi, Anesteziyoloji ve Reanimasyon Kliniği, Ankara, Türkiye

\section{GiRiş}

Propofol hızlı etkili olması ve etkisinin kısa sürede ortadan kalkması nedeniyle yoğun bakım hastalarında sedasyon amaçıı sık kullanılan bir hipnotik ajandır. İdrarın yeşil renk değişikliğine; ilaçlar, boyalar, infeksiyonlar ve diğer birçok faktör neden olabilir [1,2]. Propofol klirensi hepatik ve ekstrahepatik eliminasyonu aştığında propofol nedenli yeşil idrar ortaya çıkmaktadır. Bu renk değişikliği enderdir fakat propofolun nefrotoksik olmayan ve ilacın kesilmesinden sonra geri dönebilen benign bir yan etkisidir ${ }^{[1-5]}$.
Bu makalede, 34 yaşında şiddetli preeklempsi ve HELLP sendromu ön tanılarıyla acil sezaryen ameliyatına alınan ve postoperatif dönemde yoğun bakımda mekanik ventilasyon desteği almakta iken, sedasyon amaçlı başlanan propofol infüzyonuna bağlı idarda yeşil renk değişikliği gelişen hasta sunulmuştur.

\section{OLGU SUNUMU}

Preeklempsi ön tanılı 34 yaşında, 70 kg, 163 cm gebe hasta kadın doğum tarafından spinal anestezi ile acil sezaryen ameliyatına alındı. İntraoperatif kan basıncı 
yüksek seyreden hasta postoperatif yakın takip amaçlı anestezi yoğun bakım ünitesine yatırıldı. Arterial kan basıncının 210/115 mmHg olarak saptanması üzerine, nitrogliserin (Perlinganit ${ }^{\circledR}$ ) 0.25 $\mu \mathrm{g} / \mathrm{kg} / \mathrm{dk}$ infüzyonu başlanıldı. Yoğun bakım takiplerinin 10. saattinde hasta da ani bilinç kaybı ve jeneralize tonik klonik nöbet gelişti. Nöbet midazolam ile durdurulmaya çalışıldı ve solunumu yüzeyelleşen hasta entübe edilip mekanik ventilasyon desteği sağlandı. Hastaya sedasyon amaçı $5 \mathrm{mg} / \mathrm{saat}$ midazolam (Dormicum ampül $15 \mathrm{mg} / 5 \mathrm{ml}$, Roche, İstanbul) infüzyonu başlandı. Arteryal kan basıncı ve laboratuvar parametreleri yakın takip edildi. Refrakter hipertansiyon için kombine antihipertansif tedavi başlanıldı. Kranial BT ve kranial difüzyon MRG ile nöroloji konsültasyonu yapılan hasta klinik ve radyolojik olarak Posterior Reversibi Ensefalopati Sendromu (PRES) ile uyumlu değerlendirildi. Hematoloji bölümü tarafından, laboratuvar sonuçları ve PY (periferik yayma) bulguları ile HELLP sendromu olduğu belirlendi ve hastaya gün aşırı plazmaferez uygulandı. Plazmaferez sırasında replasman mayi olarak taze donmuş plazma kullanıldı. Üçüncü plazmaferez sonrası olgunun periferik oksijen satürasyonlarında düşme arttı. Arteriyel kan gazı hipoksemik ve hiperkarbik olarak değerlendirildi. Akciğer grafisinde bilateral diffüz infiltrasyon saptandı. Olguda gelişen solunum yetmezliği, transfüzyon ilişkili dolaşım yüklenmesi olarak değerlendirildi. Olgunun mekanik ventilatör modu değiştirildi ve tedaviye diüretik, steroid eklendi. Hemodinamisi ve laboratuvar bulguları stabil seyretmeyen hasta mekanik ventilatöre bağlı ve sedatize olarak takip edildi. Hastaya toplamda 6 ünite eritrosit süspansiyonu, 2 ünite tam kan ve 1 ünite eferez trombosit verildi. Hemotoloji bölüm önerileri de alınarak takiplerinin 5. gününde kontrol PH (Periferik yayma), LDH, AST, ALT, PLT değerlerinin normal görülmesi üzerine plazmaferez sonlandırıldı ve sedatif ajan $2.0-3.0 \mathrm{mg} / \mathrm{kg} / \mathrm{h}$ propofol (Propofol \%2 Fresenius, $20 \mathrm{mg} / 1 \mathrm{~mL}$ flakon) ile değiştirildi. O zamanda, total bilirubin $1.25 \mathrm{mg} / \mathrm{dL}$, serum albumini $2 \mathrm{~g} / \mathrm{dL}$, Plt: $98.000 \mathrm{~mm}^{3}$, Hg: 11.6 $\mathrm{g} / \mathrm{dL}$ idi. Arteryal kan gazı analizinde $\mathrm{pH} 7.41, \mathrm{pO}_{2}$
$199 \mathrm{mmHg}, \mathrm{pCO}_{2} 45.8 \mathrm{mmHg}$ ve $\mathrm{HCO}_{3} 24.7 \mathrm{mEq} / \mathrm{L}$ idi. Kan basıncı: 160/90 mmHg, kalp hızı: 101 atım/dk., $\mathrm{SpO}_{2}$ : \%99 olarak görüldü. Sürekli propofol infüzyonunun 40. saatinde hastanın idrarında yeşil renk değişikliği görüldü (Şekil 1). Hastanın tam kan sayımı, arterial kan gazı, karaciger ve böbrek fonksiyon testleri normaldi. İdrar mikroskopisi; pH 7.0, Dansite 1.012, glukoz normal, ketonbilirubin negatif, ürobilinojen $+4 \mathrm{mg} / \mathrm{dL}$ idi. Olası bir enfeksiyöz patolojiyi ekarte etmek için idrarkan kültürleri gönderildi ve negatif sonuçlandı. idrar rengini değiştiren herhangi bir ilaç ve infeksiyon belirtisi olmadığı için yeşil idrar nedeni olarak propofol infüzyonundan kuşkulanıldı. Toplam propofol dozu $8.400 \mathrm{mg}$ idi. İdrar renginin propofol infüzyonu kesildikten 6 saat sonra normal rengine döndüğü görüldü. Hemodinamisi stabil seyreden ve bilinci açılan hasta extübe edilerek maske oksijen ile takip edildi. Hasta yatışının 10. günü medikal tedavisinin devamı amaçlı kadın doğum servisine alındı.

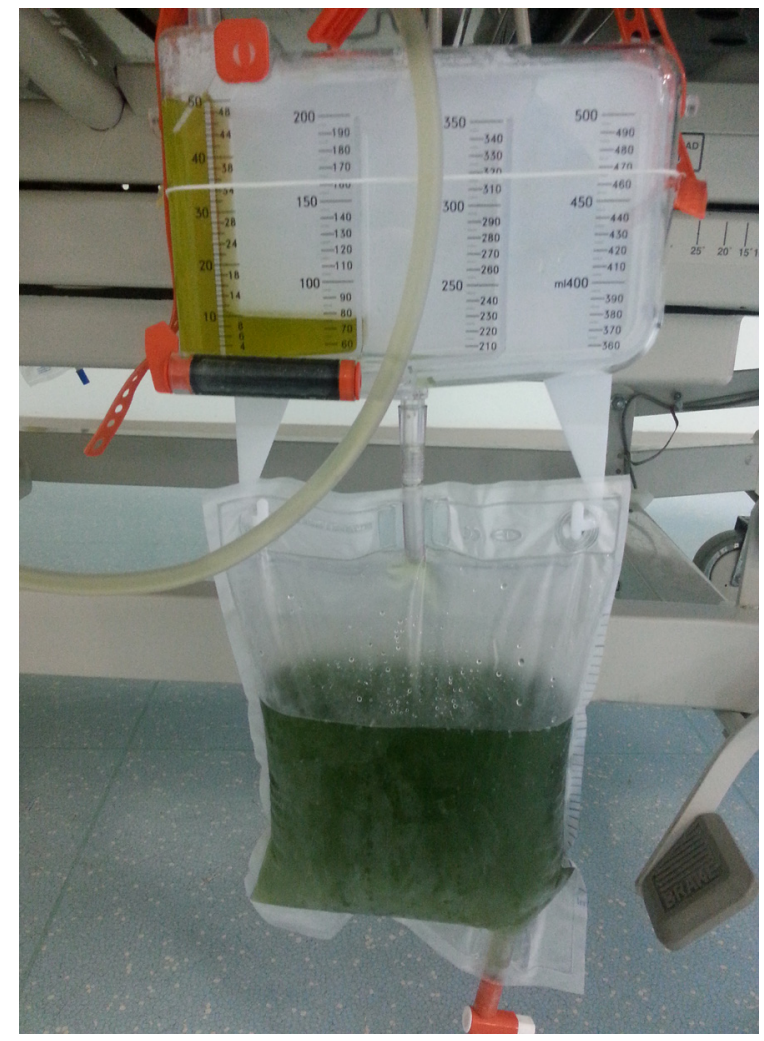

Resim 1. Propofol infüzyonunun 40. saatinde idrar rengi. 


\section{TARTIŞMA}

Propofol genel anestezinin indüksiyon ve idamesinde veya yoğun bakımda kritik hastalarda sedasyon amaçlı yaygın olarak kullanılan kısa etkili bir intravenöz hipnotik ajandır ${ }^{[1,2]}$. Propofol infüzyonu sonrası idrarda yeşil renk değişikliği benign, geri dönüşümlü ve ender olarak karşılaşılan bir klinik fenomendir. Yaygın kullanımı göz önüne alındığında, bildirilen olgulara dayanarak \%1'den daha az bir sıklık ile propofol infüzyonuna bağlı yeşil idrarın saptanması olağan dışı ve ender bir durumdur ${ }^{[2-5]}$.

İdrar renginde herhangi bir değişiklik hastalıkların değerlendirilme aşamasında teşhise büyük yardımcı olabilmektedir. İdrarın renk değişikliği yoğun bakım ortamında ilaçlar, tıbbi hastalıklar, boyalar ve yiyecekler gibi birçok faktör tarafından meydana gelebilir ve idrar rengindeki değişikliği not etmek klinisyenin tedavi yaklaşımı için çok önemlidir ${ }^{[1-3]}$. Normal olarak taze idrar berrak sarı-sarı renkte görünür. Yeşil idrar bazı ilaçlarla ilişkilendirilebilir. Promethazine, timol ve propofol gibi fenol gruplarını içeren ilaçlar, metoklopramid, amitriptilin ve indometasin gibi bazı fenol dışı ilaçların yeşil idrar ürettiği bilinmektedir. Ayrıca boyalar veya idrar yolu infeksiyonları da idrarın rengini yeşile değiştirebilir ${ }^{[2,3]}$ (Tablo 1).

Tablo 1. Yeşilimsi idrar renk değişikliğinin yaygın nedenleri ${ }^{[3]}$.

\begin{tabular}{ll} 
Neden & Materyal \\
\hline $\begin{array}{l}\text { Fenol içeren } \\
\text { bileşikler }\end{array}$ & Prometazin, propofol, timol \\
Boyalar & $\begin{array}{l}\text { Indigo mavi, metilen mavisi (mavimsi yeşil), } \\
\text { Fenol asit, gıda boyaları, Biliverdin }\end{array}$ \\
İlaçlar & $\begin{array}{l}\text { Amitriptilin, Simetidin, Indometasin, } \\
\text { Metoklopramid }\end{array}$ \\
Infeksiyon & Pseudomonas \\
\hline
\end{tabular}

Propofole bağlı idrarın yeşil renk değişikliğinin patofizyolojisi henüz açıkça ortaya koyulamamıştır. Propofol, yalnızca karaciğer ve ince bağırsaklar tarafından değil, aynı zamanda böbrekler tarafından da metabolize edilir. İdrar rengi; kabızlık, bozulmuş peristaltizm ve buna bağlı bozulmuş entero-hepatik dolaşım, albumin ve eritrositlerin taşıyıcı protein olarak kullanılması, sürekli propofol infüzyonu alan hastalarda çoğunlukla böbreklerde meydana gelen ekstra-hepatik glukuronidasyon nedeniyle yeşile dönebilir ${ }^{[3]}$.

Propofol esas olarak karaciğerde konjuge ve metabolize edilir ve ağırlıklı 1-glukuronid, 4-glukuronid 2,6diizopropil-1,4 quinone ve 4-sülfat konjugatları olarak idrarla atılır. İdrarın yeşil rengi bu fenolik metabolitlerin ve kinol türevlerinin varlığına bağlı olduğu düşünülmektedir. Bu metabolitler biyolojik olarak aktif değildir ve bu nedenle renal fonksiyonu değiştirmezler. Bu renk değişimi propofol eliminasyonunun hepatik kapasiteyi aşıp eksrahepatik eliminasyon oluştuğu zaman meydana gelmektedir ${ }^{[4,5]}$. Hem bilirubin hem propofol serum albuminine bağlanabilir. Propofolün albümin içindeki aynı bölgeye bağlanan diğer ilaçlarla rekabet etmesi olasıdır. Propofol, eritrositlere ve esas olarak serum albüminine sıkıca bağlanır (Saf albumin çözeltilerinde \%95 bağlanır). Bu bağlanmadaki \%25'lik azalmada hipoalbümineminin önemli bir rolü olabilir ${ }^{[5]}$. Bizim olgumuzda da eritrosit transfüzyonu ve albumin replasmanı yapılmıştır. Genel olarak, artan idrar ürobilinojen seviyelerinin parankimal karaciğer hasarını gösterdiği bilinir ve hastamızda da yükseldiği (ürobilinojen $+4 \mathrm{mg} / \mathrm{dL}$ ) gözlenmiştir ${ }^{[6]}$. Bu idrarın yeşil renk değişimi ile sonuçlanan karaciğerin fonksiyon bozukluğu durumuna işaret etmektedir.

Pseudomonas ile ilişkili idrar yolu infeksiyonu, özellikle diyabet hastalarında piyosiyanin ve pyoverdin pigmentlerinin üretimi nedeniyle yeşil idrar gelişimine neden olmaktadır ${ }^{[7]}$. Hastamız diyabetik değildi, idrar mikroskobu ve idrar kültüründe infeksiyon bulguları yoktu. Bu durumun klinisyen tarafından geri dönüşümlü propofole bağlı yeşil idrardan ayırt edilmesi önemlidir.

Yeşil idrar genellikle uzun süreli propofol infüzyonu alan hastalarda bildirilmiş olsa da, genel anestezi indüksiyonunda olduğu gibi kısa süreli kullanımda da 
olgular bildirilmiştir ${ }^{[8]}$. Propofol infüzyonunun toplam miktarı yeşil idrar değişimi ile ilişkili görünmemektedir (olgumuzda yaklaşık $44.000 \mathrm{mg}$ propofol). Jang Sam L ve ark. rapor ettikleri 3 olgu da devamlı propofol infüzyonlarının farklı dozlarında (yaklaşık olarak $23.500 \mathrm{mg}, 4.720 \mathrm{mg}$ ve $2.720 \mathrm{mg}$ ) renk değişiminin meydana geldiğini belirtmişlerdir ${ }^{[8]}$. Bununla birlikte, 100 veya 200 mg'lık tek bir dozu takiben propofol kaynaklı yeşil idrar değişim durumları da vardır ${ }^{[8,9]}$. Süre olarak, Blakey SA ve ark. ${ }^{[9]}$ renk değişikliğinin infüzyonun 3 . gününde görüldüğünü belirtmişlerdir. Lee JS ve ark.'nın ${ }^{[8]}$ sundukları üç olguda sırasıyla infüzyonun 6 . saat, 19 . saat ve 64 . saatinde renk değişimini rapor etmişlerdir. Olgumuzda ise infüzyonun 40. saatinde renk değişimi gözlenmiştir. Sonuç olarak, yeşil idrar renk değişiminin infüzyonun süresi veya uygulanan propofol miktarından çok, ekstrahepatik metabolizmayı kolaylaştıran durumlar ile ilişkili olduğu görülmüştür ${ }^{[10]}$.

İlginç bir şekilde, propofole bağlı idrarda ürik asitin çökelmesi nedeniyle pembe ${ }^{[11]}$ ve beyaz idrar gelişebilir ${ }^{[12]}$. Propofole bağlı idrarda renk değişikliği raporlarının tümü incelendiğinde, tüm olgularda idrar renginde propofol infüzyonunun kesilmesiyle normale geri dönüş olmuştur. Hastamızda propofol infüzyonunun kesilmesinden 6 saat sonra idrar rengi sarıya dönmüştür. Literatürde, propofol infüzyonunun kesilmesinden 2 saat- 2 gün sonra idrarın sarıya döndüğü bildirilmiştir ${ }^{[13]}$.

Propofol infüzyon sendromu (PRIS); propofol infüzyonuna bağlı yeşil idrardan farklı endişe verici ve şiddetli bir klinik tablodur. Son kanıtlar, bu sendromun, hücre işlev bozukluğuna yol açan bozulmuş serbest yağ asidi metabolizmasının ve kalp ve periferik kas nekrozunun bir sonucu olarak ortaya çıktığını göstermektedir. PRIS genellikle fetal kardiyak ve renal yetmezliğe neden olur. Tipik semptomları laktik asidoz, aritmi, hipotansiyon, renal, kardiyak ve dolaşımsal yetmezlik, oligüri, rabdomiyoliz, yüksek serum $\mathrm{CK}$, üre, potasyum seviyeleri, lipemik plazma, karaciğerde büyüme, ketonüri, yüksek karaciğer enzimleri, yeşil veya kırmızı idrardır ${ }^{[14]}$. Genç A ve ark. kafa trav- ması sonrası yoğun bakımda takip ettikleri olguda PRIS'e dair ilk bulgunun infüzyonun 60 . saatinde idrarın yeşil renk değişikliği olduğunu belirtmişlerdir ${ }^{[15]}$. Bu kritik sendromun önlenmesi ve erken tespiti için 4 $\mathrm{mg} / \mathrm{kg} / \mathrm{h}^{\prime}$ lik bir propofol infüzyon hızı aşılmamalıdır ${ }^{[16]}$.

\section{SONUÇ}

Propofol infüzyonu alan bir hastada ender de olsa geri dönüşümlü ve benign propofole bağlı yeşil idrarın gelişebileceği akılda tutulmalıdır. Ayırıcı tanıda ilaçlar, boyalar, tüketici ürünleri ve infeksiyonlar akla gelmelidir. Bu renk değişikliğinin erken tanınması, geniş spektrumlu antibiyotiklerin kullanılmasını vazgeçirmesi ve gereksiz laboratuvar testlerini (idrar analizi, idrar kültürü, tam kan kültürü) önlemesi açısından önemlidir. Sonuç olarak, klinisyenler ilaçların nadir yan etkilerinin farkındalığı konusunda uyanık olmalılardır.

\section{KAYNAKLAR}

1. Kim GE, Kim DY, Yoo DK, Lee JH, Lee SM, Min JJ. Green urine after general anesthesia with propofol: different responses in the same patient-a case report. Anesth Pain Med. 2017;12:32-6.

https://doi.org/10.17085/apm.2017.12.1.32

2. Bryson HM, Fulton BR, Faulds D. Propofol: An update of its use in anaesthesia and conscious sedation. Drugs. 1995;50(3):513-59. https://doi.org/10.2165/00003495-199550030-00008

3. Demir T, Aslan K, Balal M, Bicakci S, Bozdemir H. Green urine appearance in a patient with refractory status epilepticus due to propofol infusion. J Clin Anal Med. 2018;9:150-2.

https://doi.org/10.4328/JCAM.5327

4. Shioya N, Ishibe Y, Shibata S, et al. Green urine discolouration due to propofol infusion: A Case report. Case Reports in Emergency Medicine. 2011;2011:242514. https://doi.org/10.1155/2011/242514

5. Barbara DW, Whalen FX. Propofol induction resulting in green urine discolouration. Anaesthesiology. 2012;116:924.

https://doi.org/10.1097/ALN.0b013e31823a13bc

6. Zhou R, Liu R. Does bilirubin change the free concentration of propofol? Acta Anaesthesiologica Scandinavica. 2010;54(5):653-4 https://doi.org/10.1111/j.1399-6576.2009.02172.x

7. Keiko FA, Hiroshi K, Haruhisa F. An analysis of green discoloration of urine caused by propofol infusion. Journal of Clinical Anesthesia. 2016;35:358-60. https://doi.org/10.1016/j.jclinane.2016.08.032

8. Lee JS, Jang HS, Park BJ. Green discolouration of urine after propofol infusion. Korean Journal of 
Anaesthesiology. 2013;65(2):177-9. https://doi.org/10.4097/kjae.2013.65.2.177

9. Blakey SA, Hixson-Wallace JA. Clinical significance of rare and benign side effects: propofol and green urine. Pharmacotherapy. 2000;20:1120-2. https://doi.org/10.1592/phco.20.13.1120.35041

10. Lee YC, Lee JN, Bae JS, Park YC. Green urine in a patient who received a continuous infusion of propofol - A case report. Korean J Anesthesiol. 2009;56:325-7. https://doi.org/10.4097/kjae.2009.56.3.325

11. Masuda A, Hirota K, Satone T, Ito Y. Pink urine during propofol anesthesia. Anesth Analg. 1996;83:666-7. https://doi.org/10.1213/00000539-199609000-00070

12. Nates J, Avidan A, Gozal Y, Gertel M. Appearance of white urine during propofol anesthesia. Anesth Analg. 1995;81:210.

https://doi.org/10.1213/00000539-199507000-00058
13. Rawal G, Garg N, Wani UR, Yadav S. Green urine: A rare benign side effect of Propofol. Int J Med Res Rev. 2015;3(1):136-8. https://doi.org/10.17511/ijmrr.2015.i1.24

14. Motsch J, Roggenbach J. Propofol infusion syndrome. Anaesthesist. 2004;53:1009-22. https://doi.org/10.1007/s00101-004-0756-3

15. Genç A, Yılmaz MB, Canpolat DG, Behret O. Careful with Propofol Use in Head Trauma! Propofol Infusion Syndrome at Low Dose in an Adolescent. J Nervous Sys Surgery. 2014;4(4):201-4.

https://doi.org/10.5222/sscd.2014.201

16. Tezcan AH, Öterkuş M, Dönmez I, Öztürk Ö, Yavuzekinci Z. A Mild Type Propofol Infusion Syndrome Presentation in Critical Care. Kafkas J Med Sci. 2018;8(1):61-3.

https://doi.org/10.5505/kjms.2018.32154 